\title{
Identifying Early Neuropsychological Indicators of Cognitive Involvement in Multiple Sclerosis
}

This article was published in the following Dove Press journal:

Neuropsychiatric Disease and Treatment

\section{Elizabeth S Gromisch (iD) ${ }^{1-4}$ Zaenab Dhari ${ }^{1,2}$}

'Mandell Center for Multiple Sclerosis, Mount Sinai Rehabilitation Hospital, Trinity Health Of New England, Hartford, CT, USA; ${ }^{2}$ Department of Rehabilitative Medicine, Frank H. Netter MD School of Medicine at Quinnipiac University, North Haven, CT, USA; ${ }^{3}$ Department of Medical Sciences, Frank H. Netter MD School of Medicine at Quinnipiac University, North Haven, CT, USA; ${ }^{4}$ Department of Neurology, University of Connecticut School of Medicine, Farmington, CT, USA
Correspondence: Elizabeth S Gromisch 490 Blue Hills Avenue, Hartford, CT, 06112 , USA

Tel +860-7| $4-2154$

Fax +860-7|4-8933

Email elizabeth.

gromisch@trinityhealthofne.org

\begin{abstract}
Multiple sclerosis (MS) is a debilitating disease of the central nervous system that is most commonly seen in early to middle adulthood, although it can be diagnosed during childhood or later in life. While cognitive impairment can become more prevalent and severe as the disease progresses, signs of cognitive involvement can be apparent in the early stages of the disease. In this review, we discuss the prevalence and types of cognitive impairment seen in early MS, including the specific measures used to identify them, as well as the challenges in characterizing their frequency and progression. In addition to examining the progression of early cognitive involvement over time, we explore the clinical factors associated with early cognitive involvement, including demographics, level of physical disability, disease modifying therapy use, vocational status, and psychological and physical symptoms. Given the prevalence and functional impact these impairments can have for persons with MS, considerations for clinicians are provided, such as the role of early cognitive screenings and the importance of comprehensive neuropsychological assessments. Keywords: multiple sclerosis, early cognitive impairment, neuropsychological assessment, modifying factors
\end{abstract}

\section{Introduction}

It is estimated that there are 2.8 million people globally living with multiple sclerosis (MS), a chronic neurological condition that is most commonly diagnosed in early to middle adulthood, although it can be seen in children and older adults. ${ }^{1,2}$ About $85 \%$ of persons with MS are initially diagnosed with relapsing remitting MS (RRMS), which is characterized by relapses and stable disability in between., ${ }^{1,2}$ A diagnosis for RRMS is based on evidence of dissemination in space (ie, distinct location in the central nervous system) and in time, which is met with $\geq 2$ demyelinating episodes and $\geq 2$ lesions. $^{2}$ Individuals who have had a single episode are considered to have clinically isolated syndrome (CIS). ${ }^{2}$ Over time, RRMS may evolve to secondary progressive MS (SPMS). ${ }^{2}$ Another $12 \%$ are diagnosed with primary progressive MS (PPMS), who have had at least one year of disability progression without relapses and meet two additional criteria $(\geq 1$ periventricular, cortical/juxtacortical, or infratentorial T2- hyperintense lesions, $\geq 2$ spinal cord T2hyperintense lesions, and/or cerebrospinal fluid-specific oligoclonal bands). ${ }^{1,2}$

The clinical presentation of MS is heterogeneous, with persons presenting with range of physical and emotional symptoms. A common and often intrusive symptom of MS is cognitive impairment, which can affect up to $70 \%$ of the MS population. ${ }^{3}$ Persons with MS can experience difficulties in several cognitive domains, including 
processing speed, attention, learning and memory, and executive functioning. ${ }^{3}$ These impairments can have a negative impact on several aspects of persons' with MS lives, including their quality of life and completion of everyday activities. ${ }^{4,5}$ While more severe cognitive impairment is more likely in persons with SPMS, ${ }^{6}$ signs of cognitive involvement can be present early in the disease process.

Within the first year of diagnosis, about half of persons with MS report having either minimal or mild cognitive difficulties, with greater complaints over the first decade. ${ }^{7}$ Although uncommon, some persons with MS present with cognitive impairment as their primary symptom. ${ }^{8}$ Individuals with an aggressive form of cognitive impairment at this early stage can exhibit severe deficits reaching the level of a major neurocognitive disorder. ${ }^{9,10}$ In addition, cognitive issues may be present preclinically, with one study finding that men who developed MS two years later performed six points lower on an intelligence quotient test compared to a control group. ${ }^{11}$ As such, there is a strong need to evaluate and monitor cognitive functioning beginning early in the disease so as to detect these issues as soon as possible.

That being said, understanding the prevalence and types of cognitive involvement early in the disease process comes with challenges as there is not a clear definition of what is considered the early stage of MS. The literature is mixed, with studies characterizing early MS by disease duration (either since diagnosis or symptom onset), ${ }^{12-112}$ level of disability (such as with the Expanded Disability Status Scale; EDSS), ${ }^{11-120}$ or a combination of both metrics. ${ }^{121-158}$ Furthermore, the time frame of disease duration for early MS varies greatly. For instance, some studies defined early MS shortly after symptom onset or diagnosis (eg, six months or less), ${ }^{13,15,18,24-26,29,31,32,34,35,37,41,48,54,65,72,94,112,153,156,158}$

while other studies used broader time frames, such as 10 years or less. ${ }^{33,46,78,89,113,121,129-131}$ As some studies were investigating the signs of cognitive involvement soon after the onset of initial symptoms, persons with CIS suggestive of MS were included, either comprising the entire early stage group $17,21,26,37,47,48,54,57,58,61-64,66,68,71,79,84,92-94,99$, $101,103,107,137,142,148,153,156$ or as part of a mixed sample with persons with early RRMS. ${ }^{12,18,20,22,28,44 \text {, }}$ $53,56,67,73,75,77,80,82,83,87,105,106,108,109,112,122,143,145,146$ In contrast, studies that have examined early MS in relation to late MS have defined the latter as a disease duration of $>10^{23}$ or $>12$ years. ${ }^{19,104}$

Given the need to understand the early signs from a clinical perspective, we aimed to review the current literature on cognitive impairment that occurs early MS in order to answer the following questions: 1) what is the prevalence of cognitive involvement in early MS; 2) what types of cognitive deficits are seen in early MS and how are they measured; 3 ) how does early MS cognitive involvement evolve over time; and 4) what clinical factors are associated with early MS cognitive involvement and its progression. In order to provide a comprehensive review of the literature in this area, we utilized a broader definition of early MS (ie, 10 years or less disease duration and inclusion of persons with CIS) and discuss how the different criteria may contribute to discrepancies. Finally, we will discuss implications for clinicians, such as screening batteries for early detection and the importance of comprehensive neuropsychological assessments.

\section{Methods}

A search was conducted of articles published in English between 1991 and 2020 using PubMed, MEDLINE, and CINAHL using a combination of the search terms cognition, cognitive, neuropsychological, early, multiple sclerosis, and clinically isolated syndrome. Both pediatric-onset and adult-onset cohorts were included. A total of 2003 entries were found (Figure 1). After removing duplicate entries $(n=1126)$ and articles where only the abstract was in English $(\mathrm{n}=1)$, literature reviews, protocols, corrections, case studies, working group reports, letters to the editor, and conference abstracts $(n=299)$ were excluded. The titles and abstracts were then screened, with articles removed if they were not about $\mathrm{MS}$, including animal model-based studies $(n=87)$, or were not about cognitive functioning $(\mathrm{n}=107)$. The remaining 383 articles were split between the two authors for review. Articles were excluded if they did not fit our definition of early MS ( $\mathrm{n}=$ $138)$, only used self-reported cognitive measures $(n=4)$, or were not related to our study questions $(n=94)$. If one author was unsure if an article met the inclusion criteria, it was reviewed by the other and a consensus was reached. Due to the breadth of literature that examines neuroimaging and biomarkers with cognitive functioning in MS, it was decided to exclude these articles from the current review in order to focus on neuropsychological indicators. A total of 147 studies were included in this review.

\section{Results}

\section{Prevalence of Cognitive Impairment in Early MS}

Fifty studies provided an estimate on the prevalence of cognitive involvement in early $\mathrm{MS}$, with rates being as 

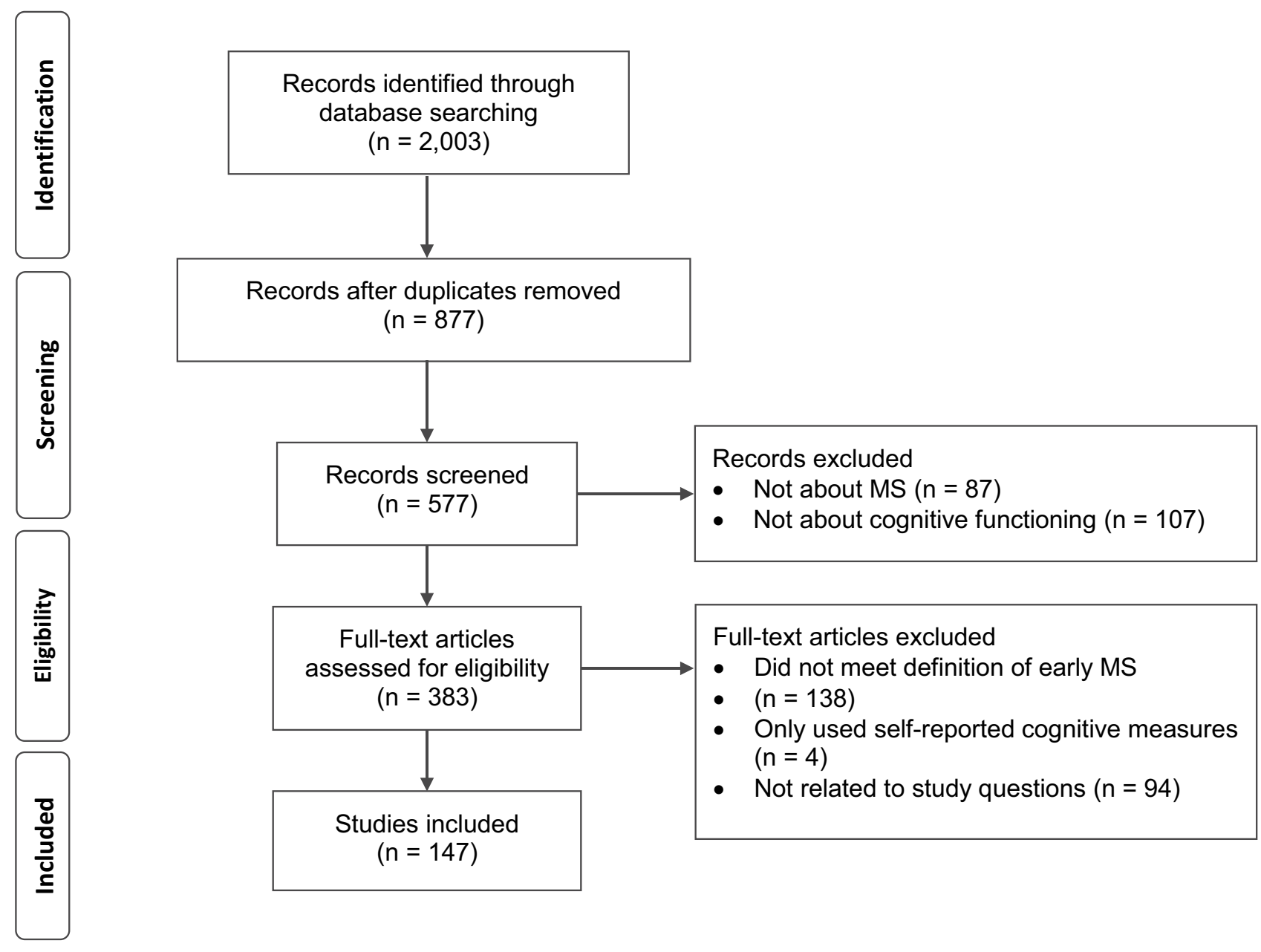

Figure I PRISMA flow diagram of article screening and selection for literature review.

Notes: PRISMA figure adapted from Liberati A, Altman D, Tetzlaff J, et al. The PRISMA statement for reporting systematic reviews and meta-analyses of studies that evaluate health care interventions: explanation and elaboration. Journal of clinical epidemiology. 2009;62(10). Creative Commons. ${ }^{183}$

high as $61 \% ;^{82}$ however, the numbers vary greatly between studies. Besides the variable definitions of early MS, there are several different criteria employed for classifying persons as cognitively impaired. Fischer et $\mathrm{al}^{19}$ identified 20 distinct approaches for defining cognitive impairment in the literature, which could be broadly grouped by 1) the number of impaired measures, 2) a composite score (ie, a z-score calculated by performance on all measures in a domain), and 3) a combination of the first two strategies. Furthermore, different stringencies for impairment have been used, such as the number of required "failed' measures and the cut-off for impairment (eg, 1.5 standard deviations (SD) below the mean). Fischer et $\mathrm{al}^{19}$ noted that using more liberal criteria could result in the prevalence of cognitive impairment in early MS being overestimated: in their own sample, the rate of cognitive impairment ranged from $0 \%$ to $68 \%$ using the 20 identified criteria. In addition, it should be kept in mind that healthy controls may demonstrate impairment, and some researchers have adjusted for this in the quantification of impairment in early MS. For instance, Baysal Kıraç et al ${ }^{12}$ adjusted the number of impaired measures required (ie, four or more measures) based on performance of their healthy controls. Deloire et $\mathrm{al}^{41}{ }^{41}$ on the other hand, calculated the attributable risk for impairment on one or two measures in their early MS cohort based on the percentage of "failures" in their control group.

As demonstrated in Table 1, several criteria have been used to define cognitive impairment during the early stage of MS. While the number of "failed" measures varied in those studies, it was often influenced by the assessment battery used. For instance, the Brief International Cognitive Assessment for MS $(B I C A M S)^{159}$ consists of three measures (Symbol Digit Modalities Test (SDMT), five learning trials of the California Verbal Learning Test-Second Edition (CVLT-II), and three learning trials of the Brief Visuospatial Memory Test- 
Table I Rates of Impairment in the Literature by Different Criteria

\begin{tabular}{|c|c|}
\hline Definition & Rates \\
\hline Impaired on a composite score $(<I .3 \mathrm{SD})^{40}$ & $39.1 \%$ \\
\hline Impaired on one or more neuropsychological measures $(<1.5 \text { SD or } 5 \text { th percentile })^{22,41,44,46,85,113}$ & $32.3-53.7 \%$ \\
\hline $\begin{array}{l}\text { Impaired on one or more neuropsychological measures } \\
(<2 \mathrm{SD})^{12,29,125,129,145,146}\end{array}$ & $29.3-56.1 \%$ \\
\hline $\begin{array}{l}\text { Impaired on one or more cognitive domains } \\
(<2 \mathrm{SD})^{47,51}\end{array}$ & $22-29 \%$ \\
\hline Impaired on two or more neuropsychological measures ( $<1.5 \mathrm{SD}$ or 5 th percentile) $)^{18,22,25,31,32,34,39,41,44,62,84,85,113,135,153}$ & $10.8-52.3 \%$ \\
\hline 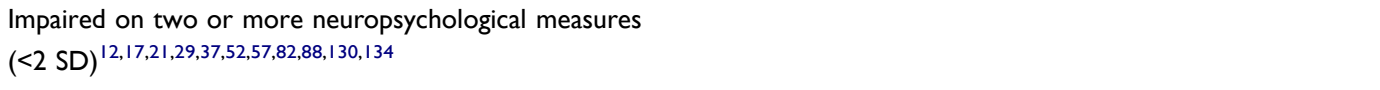 & $6.6-61 \%$ \\
\hline $\begin{array}{l}\text { Impaired on two or more cognitive domains } \\
(<1.5 \mathrm{SD} \text { or } 5 \text { th percentile })^{27,58,59,115}\end{array}$ & $34.5-57.5 \%$ \\
\hline Impaired on three or more neuropsychological measures $(<\mid S D)^{120}$ & $21.4 \%$ \\
\hline Impaired on three or more neuropsychological measures $(<1.5$ SD or 5th percentile) $25,32,49,62,64,71,85,92,96,113,133,138$ & $4.6-47.8 \%$ \\
\hline Impaired on three or more neuropsychological measures $(<2 \mathrm{SD})^{12,13,17,29,45,150}$ & $1 \mathrm{I}-39.6 \%$ \\
\hline $\begin{array}{l}\text { Impaired on four or more neuropsychological measures } \\
(<1.5 \mathrm{SD} \text { or } 5 \text { th percentile })^{62}\end{array}$ & $13 \%$ \\
\hline $\begin{array}{l}\text { Impaired on four or more neuropsychological measures } \\
(<2 \mathrm{SD})^{12}\end{array}$ & $19.6 \%$ \\
\hline Impaired on one-third of the neuropsychological indices $(<\mid S D)^{67,106}$ & $32-37.3 \%$ \\
\hline
\end{tabular}

Revised (BVMT-R)), and impairment on one measure is considered the threshold. ${ }^{113}$ Using that criterion, $32.3 \%$ of Marstrand et al' sample ${ }^{113}$ were categorized as cognitively impaired; if held to the standard of three impaired measures (ie, the entire battery), the percent of participants categorized as impaired dropped to $4.6 \%$. On the other hand, with a more extensive battery, a higher number of "failed" measures would be more appropriate. For instance, Jønsson et al, ${ }^{27}$ who had 30 cognitive variables, identified mild impairment if at least five measures were impaired, while severe was defined as 20 or more. They also defined mild, moderate, and severe cognitive impairment by the number of impaired cognitive domains.

\section{Types of Deficits and the Measures Used to Identify Signs of Cognitive Involvement in Early MS}

Eighty studies detailed the specific measures where persons with early MS have been impaired, with deficits in several cognitive domains, including attention, processing speed, working memory, verbal learning and memory, visual learning and memory, executive functioning, language, and to a lesser extent visuospatial ability and theory of mind (Supplementary Table 1). These signs of cognitive involvement were identified either through persons with early MS performing below a specific threshold (eg, 1.5 $\mathrm{SD}$ below the normative mean) or in comparison to a matched cohort of healthy controls. Even if persons with early MS do not meet the threshold for being categorized as cognitively impaired, they may still exhibit relative difficulties. For instance, Pitteri et $\mathrm{al}^{49}$ found that their "cognitively normal" group performed worse on measures of verbal learning and memory, attention and processing speed, and executive functioning compared to healthy controls.

Although the measures used varied between studies, two of the most commonly used measures that have 
detected early cognitive involvement were the SDMT and the Paced Auditory Serial Addition Test (PASAT). Fortyone studies found impairments in early MS using the SDMT, a 90 -second measure where the examinee orally matches numbers to corresponding symbols as quickly as possible. ${ }^{160}$ The SDMT has emerged as a particularly sensitive measure, with one study finding that it correctly classified $75.4 \%$ of their sample with cognitive impairment. ${ }^{41}$ Thirty-four studies identified deficits with either the 3-second or 2-second version of the PASAT, where the examinee attends to and calculates numbers that are presented auditorily via a tape recording. ${ }^{161}$ Besides issues with complex attention, processing speed, and working memory, persons with early MS have also demonstrated slowed reaction time on attentional measures, although measurement of this metric was less common in the identified studies.

Issues with learning and memory can emerge early in the disease process. Thirty-six studies showed that persons with early MS exhibit difficulty learning and recalling verbal information. The most commonly used measure was the Selective Reminding Test (SRT), which 18 studies found impairments on, particularly on the Long Term Storage, Consistent Long Term Retrieval, and Delayed Recall indices. Besides the SRT, other measures that detected impairments were the CVLT-II (four studies) and the Rey Auditory Verbal Learning Test (RAVLT; six studies). Difficulty learning and remembering visual material was also observed, as noted by 34 studies. The Spatial Recall Test (SPART) was used the most frequently, with issues being identified in 15 studies, particularly on the Delayed Recall index. Impairments were also found in nine studies using the BVMT-R.

While several studies have focused on attention, processing speed, and memory impairments in early MS, executive dysfunction can also occur, as noted by 26 studies. Pitteri et $\mathrm{al}^{49}$ found that $71 \%$ of their sample exhibited deficits on a composite executive functioning index, although other studies have found much lower rates of impairment. ${ }^{125}$ As executive functioning in a broad term, several different processes such as setshifting (eg, Trail Making Test Part B; TMT-B; eight studies), inhibition (eg, Stroop; 10 studies), and abstraction (eg, Similarities from the Wechsler Adult Intelligence Scale; four studies) can be included in this domain. Verbal fluency has sometimes been included as executive functioning tasks, ${ }^{49}$ in addition to being a language-based task. Deficits in both phonemic (ie, letter) and semantic (ie, category) fluency have emerged in 15 studies and 16 studies, respectively, as signs of early cognitive involvement. Furthermore, with persons with CIS, both verbal fluency tasks were able to classify individuals with cognitive impairment with $64-82 \%$ sensitivity and $66-79 \%$ specificity. ${ }^{17}$

However, because of the heterogeneity of these samples, the types of impairments observed are not consistent across studies. For instance, in their sample of persons with CIS, Viterbo et al noted only 5-7\% were impaired on the SDMT and PASAT, while other studies ${ }^{103,121}$ did not find differences between healthy controls and persons with early MS on PASAT or SDMT performances. In addition to the different definitions for early MS, another consideration may be in how the measure is utilized and scored, such as in the case of the PASAT where examiners may look at total correct scores, dyads, and/or performance at different points of the test. When Berard et al ${ }^{121}$ used it to measure cognitive fatigue (eg, performance on the last third of the task compared to the first third), persons with early MS exhibited significantly greater difficulties.

In addition to cognitive involvement becoming more prevalent in late MS, ${ }^{19,58,79,84,88,104}$ as the disease progresses, some of these cognitive difficulties may become more apparent. For instance, Achiron et $\mathrm{al}^{79}$ found that the percent of persons with MS with cognitive impairment significantly increased after five years of MS onset, while Štecková et a ${ }^{87}$ noted greater impairments among persons who had had MS for 10 years compared to persons with CIS and persons with MS for five years. In terms of specific deficits, while Caputi et al ${ }^{128}$ found that persons with early RRMS did not differ from healthy controls in terms of object naming and visual discrimination, deficits were more pronounced in later stages of the disease (ie, SPMS). Processing speed and memory performances have also been shown to be lower in late MS compared to early MS. $^{23,104,157}$

\section{Evolution of Early Cognitive Impairment}

In addition to studies comparing MS cohorts at different stages of the disease, there have been 24 longitudinal studies with persons with early MS. While some studies did not observe a decline on individual ${ }^{121}$ or a battery of measures, ${ }^{106,131,153}$ several identified an increase in cognitive impairments over time. For instance, Amato et al ${ }^{133}$ noted that the number of persons with MS with no cognitive impairment decreased from $74 \%$ at baseline to $44 \%$ at 
the 10-year follow-up, with a particular increase in the number with mild cognitive impairment ( $8 \%$ to $34 \%$ ). Increases in the number of persons with cognitive involvement have also been observed at two years, ${ }^{134,149}$ three years, ${ }^{115,135}$ four years, ${ }^{132}$ five years, ${ }^{47,51,60,112,136}$ seven years, ${ }^{31,116}$ and nine years ${ }^{158}$ since the initial neuropsychological evaluation.

Several studies have found that the SDMT is sensitive to progression, with greater impairments noted over time. ${ }^{15,28,60,135,136,143}$ While declines in attention, processing speed, or memory were detected in several cohorts, ${ }^{31,47,60,112,116,134,158}$ this was not observed by Wybrecht et al. ${ }^{50}$ Instead, they found a greater number of persons with MS impaired in executive functioning 10 years later, particularly on the TMT-B, Digit Spans Backwards, and both phonemic and semantic fluency. ${ }^{50}$ Declines in executive functioning, including verbal fluency, have been noted in other longitudinal early MS cohorts. $^{47,134}$

While longitudinal cohorts can provide insight into the progression of early MS cognitive impairment, there are potential confounders that may skew results. Some studies have noted improvements on certain measures at the second assessment, which has been attributed to factors such as practice effects, short intervals between the initial and follow-up testing, anxiety at baseline, and initiation of disease modifying therapies (DMT) after the first evaluation. $^{18,27,121}$ Besides judging the length of time between assessments and using an equivalent alternative form of a measure, clinicians may consider calculating the reliable change to determine if a reduction in performance (or improvement) represents meaningful change.

\section{Clinical Factors Associated with Early Cognitive Involvement and Its Progression$$
\text { Demographics }
$$

When examining their patients' performances and determining whether there is evidence of cognitive impairment, clinicians should be mindful of factors that may be associated with reduced performance. Although 10 studies did not find a significant relationship between age or gender with cognitive performances in early MS, ${ }^{12,21,37,39,46,47,65,82,125,135}$ nine noted worse performance with older age or among men. ${ }^{18,24,26,30,44,52,111,133,139}$ For instance, men with early MS have demonstrated greater impairments in aspects of executive functioning and verbal learning and memory. ${ }^{30,139}$ One study ${ }^{78}$ also found that low free testosterone levels in men were related to more longitudinal changes on the SDMT.

The contributions of race and ethnicity in early MS cognitive involvement have been studied less extensively. While Black and Hispanic persons with MS had lower scores on the oral SDMT compared to White persons with MS, Amezcua et $\mathrm{al}^{20}$ attributed these findings to underlying population differences (eg, sociodemographic factors) rather a more severe disease course. The authors highlighted the importance of using appropriate normative data to identify persons in the early stages of MS who are exhibiting cognitive involvement. Julian et $\mathrm{al}^{67}$ did not find race to be a significant contributor to cognitive performance, but noted a trend with lower scores and identifying as Hispanic.

Seven studies did not demonstrated an association between education level and cognitive performance, ${ }^{39,44,46,47,65,125,135}$ while 10 showed that persons with fewer years of education have greater levels of impairment. ${ }^{17,18,21,30,37,52,72,111,113,144}$ For instance, Bonnet et $\mathrm{al}^{72}$ found that persons with early MS who had low educational levels ( $<12$ years or no schooling) were impaired on 13 out of 15 cognitive tests, while persons with high education levels were only impaired on three measures. Persons' education level has also been utilized as a marker for cognitive reserve. For instance, Barbu et $\mathrm{al}^{131}$ used years of education and performance on the North American Adult Reading Test to calculate cognitive reserve. While they did not find that cognitive reserve predict change in cognitive functioning three years later, their sample did not exhibit significant decline over time. In addition, Planche et $\mathrm{al}^{80}$ hypothesized that their sample's high education level contributed to the lack of impairment in memory impairments.

\section{Level of Disability}

There has been mixed evidence on the connection between level of disability and cognitive impairment. Fifteen studies have found relationships between disability and cognition, ${ }^{16,18,24,26,34,43,54,67,83,105,111,113,114,116,122}$ with seven studies noting that cognitive performances predicted disease progression ${ }^{13,24,32,35}$ or disability predicted cognitive deterioration. ${ }^{45,132,133}$ In 15 other cohorts, disability and cognitive performance were not significantly associated. $^{12-17-29-37-39-44-46-82-107-109-123-125,135}$ The discrepancies in these findings may be due to the 
heterogeneity of the study populations. In the studies that identified a significant relationship between cognitive impairment and disability, three included participants' EDSS score in their definition of early MS (ie, $\leq 4^{122}$ and $\leq 5^{113,132}$ ). Comparatively, three of the studies that did not find an association had a narrower EDSS inclusion criterion (ie, $\leq 2^{123}, \leq 2.5^{125}$, and $\leq 3.5^{135}$ ).

\section{Disease Modifying Therapies}

Seven studies have evaluated the impact of starting a DMT on cognitive functioning. Overall improvement in cognitive functioning have been noted with interferon beta-1a three years after initiation. ${ }^{120}$ In a pediatric cohort, ${ }^{100}$ persons with MS who had an escalation of their DMT (ie, changing to fingolimod or natalizumab) had better overall cognitive performance than individuals who remained on a first-line DMT. In terms of specific tests, improvements on the SDMT have been found with interferon beta-1a, ${ }^{91,151}$ interferon beta- $1 \mathrm{~b},{ }^{91,151}$ glatiramer acetate, ${ }^{151}$ and natalizumab, ${ }^{155}$ with a non-significant increase with the latter in a pediatric cohort with aggressive MS. ${ }^{154}$ The PASAT- $2^{91}$ and PASAT- $3^{93}$ have been noted to improve following treatment with interferon beta-1a and interferon beta-1b, respectively. Interferon beta-1a, interferon beta-1b, and glatiramer acetate have also been associated with improvements on total learning of the CVLT-II and BVMT-R. ${ }^{151}$ In addition, Mokhber et $\mathrm{al}^{91}$ noted improvements on the SPART Delay with interferon beta-1a, as well as on the SRT Delay and WLG with one version of interferon beta-1a (Avonex).

\section{Vocational Status}

Given that the average age of diagnosis is $32,{ }^{1}$ employment is a significant concern for many persons with MS Cognition has been associated with vocational status changes, ${ }^{162}$ and these issues can be apparent early in the disease course, as noted by two studies. Jongen et al ${ }^{53}$ showed that persons with MS who wanted to work fewer hours had poorer focused attention and processing speed, while individuals who wanted to change their jobs had worse episodic memory. Furthermore, the number of days that participants worked were positively associated with their working memory, focused attention, and processing speed performances. ${ }^{53}$ Evidence of early cognitive involvement may also predict later employment. Ruet et $\mathrm{al}^{31}$ demonstrated that baseline processing speed, as well as participants' decline in cognitive functioning, predicted their vocational status seven years later.

\section{Psychological Symptoms}

While depression is prevalent in $\mathrm{MS},{ }^{163}$ there is mixed evidence on its relationship with cognitive functioning. Ten studies did not find an association between performance and level of depressive symptom severity, ${ }^{29,34,37,46,83,85,113,124,135,141}$ while 14 studies found a negative impact, ${ }^{16,18,22,30,44,45,69,70,74,98,105,107,125,142}$ such as higher levels of depression among persons with cognitive impairment or worse performance on verbal fluency, aspects of executive functioning, multitasking, working memory, and processing speed tasks. There is also mixed evidence with quality of life and cognition, with two studies not finding a relationship ${ }^{82,115}$ and four studies noting a significant association. ${ }^{22,66,113,125}$ In addition, baseline memory performance has been found to predict persons' with MS health-related quality of life seven years later, ${ }^{31}$ while improvement in cognition was associated with improvement in mental health-related quality of life longitudinally. ${ }^{73}$

Less research has been done on the impact of anxiety on cognitive performance in early MS. Although six studies did not find a significant relationship, ${ }^{16,30,85,113,142,147}$ five studies ${ }^{26,45,74,98,107}$ showed that greater anxiety symptomatology was associated with worse performance on aspects of executive functioning, working memory, processing speed, immediate structured verbal learning (ie, story memory), and delayed structured verbal memory. Simioni et al $^{125}$ also found a higher prevalence of anxiety among persons with cognitive involvement.

One study ${ }^{56}$ examined the relationship between selfefficacy and cognitive performance, finding that not only was self-efficacy strongly associated with several domains, it predicted $40 \%$ of the variability of persons' with MS performance on Power of Attention and Speed of Memory and $3 \%$ on their Reaction Time Variability. While another study ${ }^{81}$ found that psychological resilience was correlated with processing speed, it was not significant after adjusting for multiple comparisons or fatigue and mood.

\section{Physical Symptoms}

Subjective reports of fatigue have not been found to be consistently related to objective cognitive performance in the wider MS literature. ${ }^{164}$ This is similar in early MS, with seven studies finding no significant relationship between fatigue and cognitive impairment. $^{12,29,34,46,89,113,135}$ Seven studies found an association, ${ }^{22,30,68,74,75,125,142}$ such as higher rates of fatigue among persons with cognitive involvement or worse 
performance on measures of verbal fluency, verbal memory, aspects of executive functioning, working memory, and processing speed. However, part of the discrepancy may be due to the measures being used. For instance, while Hyncicova et $\mathrm{al}^{142}$ showed that the SDMT was significantly related to the Energy/Fatigue scale on the Short Form-36, it was not associated with the Fatigue Severity Scale.

Two studies investigated the association between pain and cognition in early MS, with one ${ }^{142}$ noting a significant relationship between performance on the SDMT and pain ratings in persons with CIS. While the other study ${ }^{77}$ found that impaired cognitive functioning contributed to baseline unspecified pain, other factors such as fatigue played a more significant role. Furthermore, the authors did not find that it significantly impacted follow-up unspecified pain or baseline and follow-up neuropathic pain.

Five studies have evaluated the relationship between cognition and difference aspects of eye functioning. One study ${ }^{55}$ has investigated pupillary dilation with regards to cognitive functioning in early MS. The authors found that while it was not related to performance on the BICAMS when examining their entire cohort, persons with early MS who had low cognitive scores had smaller pupillary responses compared to controls with low cognitive scores. One study ${ }^{102}$ noted that saccadic initiation time was associated with performance on the written version of the SDMT, as was hand functioning, but not with the PASAT. Similarly, Clough et al $^{108}$ only found a relationship between visually guided latency saccades with late MS and not early RRMS. With regards to antisaccades, performance on the PASAT has been correlated with latency, ${ }^{103}$ error proportion, ${ }^{108}$ and error times, ${ }^{108}$ while processing speed (ie, SDMT and the Computerized Speed Cognitive Test) has been correlated with error rate. $^{103,110}$

In terms of sleep, one study ${ }^{117}$ found that self-reported daytime sleepiness was negatively correlated with performance on the BICAMS. The authors also found positive associations between cognition and pulmonary and respiratory muscle functioning, suggesting impaired functioning in these areas are related to cognitive involvement.

\section{Discussion}

Despite differences in definitions of early MS and impairment, cognitive involvement in common within the first 10 years of MS. During the early stage of MS, persons may exhibit deficits in attention, processing speed, working memory, verbal and visual learning and memory, executive functioning, and verbal fluency. Over time, these impairments can become more significant, with a greater number of individuals exhibiting cognitive involvement. While the SDMT has been shown to be sensitive to both initial

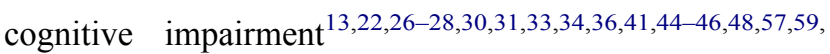
$62,64,65,68,70,76,82,86,94,97,107,109,113,114,118,127,135,140,142-144$, $148,151,156$ and progression, ${ }^{15,28,60,135,136,143}$ a number of longitudinal early MS cohorts demonstrated declines in executive functioning and verbal fluency, ${ }^{47,50,134}$ signaling the importance of evaluating and monitoring these domains over time. The evidence of modifying factors is mixed; however, several studies noted a positive influence on cognitive functioning with DMT usage $^{91,93,100,120,151,154,155}$ and cognitive reserve may help protect against decline. ${ }^{80,131}$

Given the evidence that cognitive involvement can occur early in MS and its relationship to later changes in functioning, such as vocational status, ${ }^{31}$ there is a strong need to evaluate persons' with MS cognition early and monitor over time. It is currently recommended that persons with MS should receive early baseline screening, with annual reassessment with the same measure, and a follow-up comprehensive evaluation if there is evidence of impairment. ${ }^{165}$ The minimal recommended screening tool is the SDMT or a similar validated measure, ${ }^{165}$ which coincides with our findings of its sensitivity to early cognitive involvement in MS. That said, as not all persons with MS-related cognitive impairment will demonstrate reductions on the SDMT, clinicians should strongly consider using a short screening battery that assesses several domains. The most commonly used battery is the BICAMS, which includes measures of verbal (CVLT-II) and visual (BVMT-R) learning in addition to the SDMT. ${ }^{159}$ Besides taking 15 minutes to administer, there is an international standard for validation, allowing it to be used in different countries. ${ }^{166}$

An alternative battery is the abbreviated Minimal Assessment of Cognitive Function in MS (aMACFIMS), which includes shortened versions of the SDMT, CVLT-II, BVMT-R, and verbal fluency, with both phonemic and semantic fluency in the expanded version. ${ }^{167-170}$ Deficits in verbal fluency have been noted in several early MS

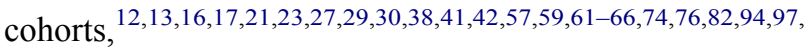
$101,118,148$ and both types have been shown to have good detection of cognitive impairment in persons with CIS, ${ }^{17}$ which supports its use as a screening battery for persons with early MS. Regardless of which screening battery 
a clinician chooses, they should be aware that they may not be capturing persons with MS whose deficits are primarily in executive functioning. Although the aMACFIMS was initially developed with an abbreviated executive functioning task (ie, one Card Sort from the D-KEFS), ${ }^{168}$ it did not significantly contribute to the battery in terms of detecting cognitive impairment and was subsequently removed. ${ }^{169}$

If there are concerns about a patient's executive abilities and/or they demonstrate impairments on a screening battery, a comprehensive neuropsychological assessment may be warranted. Besides considering the influences of demographics such as age, education, race/ethnicity, gender, and premorbid functioning on performances, a neuropsychologist can evaluate whether the person's with MS impairments are influenced by other factors such as comorbidities, ${ }^{171}$ including psychological and physical symptoms. Two of the most common batteries used in MS are the MACFIMS ${ }^{172}$ and the Brief Repeatable Battery of Neuropsychological Tests (BRB-N). ${ }^{173}$ Both of these batteries assess the domains frequently affected in early MS, including attention and processing speed (SDMT in both), working memory (PASAT in both), verbal learning and memory (CVLT-II in the MACFIMS and SRT in the BRB-N), visual learning and memory (BVMT$\mathrm{R}$ in the MACFIMS and 10/36 SPART in the BRB-N), and verbal fluency (Controlled Oral Word Association Test in the MACFIMS and Word List Generation in the BRB-N). The MACFIMS also includes measures of visuospatial functioning (Judgment of Line Orientation) and executive functioning (Delis-Kaplan Executive Function System). As the MACFIMS and BRB-N are considered minimal assessment batteries, clinicians may consider adding ones that evaluate aspects of executive functioning. For instance, a number of studies ${ }^{34,41,49,71,120}$ that used the BRB-N also included the Stroop test, which taps into inhibition. However, despite the prevalence of cognitive impairment and its impact, even in early MS, neuropsychological services may be underutilized. ${ }^{174,175}$ While there are many factors that may influence service utilization, such as cost and accessibility, increased awareness of the deficits observed at the different stages of the disease and how to screen for them may lead to more patients who need these services to receive them.

While there is a large body of literature investigating early cognitive involvement in MS, there are still limitations with the available data. The first is the lack of a consensus over what is considered "early." As previously noted, the varying definitions have likely contributed to discrepancies in the types of observed cognitive deficits and their relationships with clinical factors. Although a longer duration like $\leq 10$ years may allow for inclusion of more persons with MS from a clinical sample, it begins to encroach upon some definitions of late MS, ${ }^{23}$ making it difficult to differentiate between these stages of disease duration. Given that the rate of impairment has been shown to significantly increase after having MS for five years, ${ }^{47,51,79,112}$ classifying persons with MS with less than five years of disease duration may provide insights into the earliest signs of cognitive involvement.

In addition, the definition used for impairment can affect how many persons with MS are classified as cognitively impairment. The majority of the reviewed studies used at least a cut-off of $>1.5 \mathrm{SD}$, which is a fair stringency. ${ }^{19}$ Furthermore, the number of impaired measures is also an important factor and is dependent on the size of the battery. Several of the established batteries have a recommended number of impaired measures to consider an individual cognitively impaired: for instance, one for the BICAMS $^{13}$ and two measures for the aMACFIMS $^{169,170}$ and MACFIMS. ${ }^{176}$ With larger batteries, using a cut-off of one or two measures may overestimate the prevalence of cognitive impairment.

Finally, there is a need to evaluate how engagement in different activities and co-occurring conditions may influence cognitive functioning early in the disease process. For instance, research in the broader MS population has shown that cognitive leisure activities, which have been used as a marker for cognitive reserve, is a protective factor for cognitive decline. ${ }^{177}$ While persons with early MS tend to engage in fewer reservebuilding activities, particularly organized sports, job-related exercise, and high and low impact exercise, ${ }^{178}$ their contributions to cognitive functioning has not been explored at this stage. Furthermore, although there is evidence that there are relationships between diabetes, ${ }^{171}$ body mass index (BMI), ${ }^{171,179,180}$ and cholesterol level ${ }^{179,181,182}$ with cognition in MS, these studies were not specific to early MS. Understanding if these factors contribute to cognitive deficits early in MS may help with management of patients' multimorbidities and general health, and subsequently mediate their impact on cognitive functioning.

\section{Conclusions}

Even early in the disease process, many persons with MS can present with signs of cognitive involvement. Although the definitions for early MS and cognitive impairment vary between studies, up to $61 \%$ of persons with early MS 
demonstrate some type of cognitive involvement. Besides impairments in attention, processing speed, and memory, executive dysfunction can occur, which can include reductions in verbal fluency. As cognitive impairment can progress over time and early involvement is associated with later functional difficulties, there is a strong need for early screening and follow-up comprehensive neuropsychological assessments when indicated.

\section{Disclosure}

The authors have no conflicts of interest to report.

\section{References}

1. The Multiple Sclerosis International Federation (MSIF). Part 1: Mapping Multiple Sclerosis Around the World, Key Epidemiology Findings; 2020.

2. Thompson AJ, Banwell BL, Barkhof F, et al. Diagnosis of multiple sclerosis: 2017 revisions of the McDonald criteria. Lancet Neurol. 2018;17(2):162-173. doi:10.1016/S1474-4422(17)30470-2

3. Chiaravalloti ND, DeLuca J. Cognitive impairment in multiple sclerosis. Lancet Neurol. 2008;7(12):1139-1151. doi:10.1016/ S1474-4422(08)70259-X

4. Benito-Leon J, Morales J, Rivera-Navarro J. Health-related quality of life and its relationship to cognitive and emotional functioning in multiple sclerosis patients. Eur $j$ Neurol. 2002;9 (5):497-502. doi:10.1046/j.1468-1331.2002.00450.x

5. Kalmar JH, Gaudino EA, Moore NB, Halper J, DeLuca J. The relationship between cognitive deficits and everyday functional activities in multiple sclerosis. Neuropsychology. 2008;22(4):442. doi:10.1037/0894-4105.22.4.442

6. Planche V, Gibelin M, Cregut D, Pereira B, Clavelou P. Cognitive impairment in a population-based study of patients with multiple sclerosis: differences between late relapsing- remitting, secondary progressive and primary progressive multiple sclerosis. Eur j Neurol. 2016;23(2):282-289. doi:10.1111/ene.12715

7. Kister I, Bacon TE, Chamot E, et al. Natural history of multiple sclerosis symptoms. Int $J$ MS Care. 2013;15(3):146-158. doi:10.7224/1537-2073.2012-053

8. Evlice A, Demir T, Kaleağası C, Özcan F, Demirkıran M. Rare onset symptoms in multiple sclerosis. Acta Clin Belg. 2016;71 (3):154-157. doi:10.1080/17843286.2016.1147675

9. Assouad R, Louapre C, Tourbah A, et al. Clinical and MRI characterization of MS patients with a pure and severe cognitive onset. Clin Neurol Neurosurg. 2014;126:55-63. doi:10.1016/j. clineuro.2014.08.018

10. Mendes MF, Finkelsztejn A, Gomes S, Fragoso YD. Early and severe cognitive impairment in multiple sclerosis. Dementia Neuropsychol. 2012;6(1):48-52. doi:10.1590/S1980-57642012DN06010008

11. Cortese M, Riise T, Bjørnevik K, et al. Preclinical disease activity in multiple sclerosis: a prospective study of cognitive performance prior to first symptom. Ann Neurol. 2016;80(4):616-624. doi:10.1002/ana.24769

12. Baysal Kıraç L, Ekmekçi Ö, Yüceyar N, Sağduyu Kocaman A. Assessment of early cognitive impairment in patients with clinically isolated syndromes and multiple sclerosis. Behav Neurol. 2014;2014. doi:10.1155/2014/637694

13. Carotenuto A, Moccia M, Costabile T, et al. Associations between cognitive impairment at onset and disability accrual in young people with multiple sclerosis. Sci Rep. 2019;9(1):1-8. doi:10.1038/s41598-019-54153-7
14. Dujardin K, Donze A, Hautecoeur P. Attention impairment in recently diagnosed multiple sclerosis. Eur j Neurol. 1998;5 (1):61-66. doi:10.1046/j.1468-1331.1998.510061.x

15. Hankomäki E, Multanen J, Kinnunen E, Hämäläinen P. The progress of cognitive decline in newly diagnosed MS patients. Acta Neurol Scand. 2014;129(3):184-191. doi:10.1111/ane.12161

16. Siepman T, Janssens A, de Koning I, Polman C, Boringa J, Hintzen R. The role of disability and depression in cognitive functioning within 2 years after multiple sclerosis diagnosis. J Neurol. 2008;255(6):910. doi:10.1007/s00415-008-0814-x

17. Viterbo R, Iaffaldano P, Trojano M. Verbal fluency deficits in clinically isolated syndrome suggestive of multiple sclerosis. J Neurol Sci. 2013;330(1):56-60. doi:10.1016/j.jns.2013.04.004

18. Johnen A, Bürkner P-C, Landmeyer NC, et al. Can we predict cognitive decline after initial diagnosis of multiple sclerosis? Results from the German National early MS cohort (KKNMS). J Neurol. 2019;266(2):386-397. doi:10.1007/s00415-018-9142-y

19. Fischer M, Kunkel A, Bublak P, et al. How reliable is the classification of cognitive impairment across different criteria in early and late stages of multiple sclerosis? J Neurol Sci. 2014;343 (1-2):91-99. doi:10.1016/j.jns.2014.05.042

20. Amezcua L, Smith JB, Gonzales EG, Haraszti S, Langer-Gould A. Race, ethnicity, and cognition in persons newly diagnosed with multiple sclerosis. Neurology. 2020;94(14):e1548-e1556. doi:10.1212/WNL.0000000000009210

21. Diker S, Has AC, Kurne A, Göçmen R, Oğuz KK, Karabudak R. The association of cognitive impairment with gray matter atrophy and cortical lesion load in clinically isolated syndrome. Mult Scler Relat Disord. 2016;10:14-21. doi:10.1016/j.msard.2016.08.008

22. Glanz BI, Healy BC, Rintell DJ, Jaffin SK, Bakshi R, Weiner HL. The association between cognitive impairment and quality of life in patients with early multiple sclerosis. J Neurol Sci. 2010;290 (1-2):75-79. doi:10.1016/j.jns.2009.11.004

23. Brissart H, Morele E, Baumann C, et al. Cognitive impairment among different clinical courses of multiple sclerosis. Neurol Res. 2013;35(8):867-872. doi:10.1179/1743132813Y.000000 0232

24. Moccia M, Lanzillo R, Palladino R, et al. Cognitive impairment at diagnosis predicts 10-year multiple sclerosis progression. Multiple $\mathrm{Scl}$ J. 2016;22(5):659-667. doi:10.1177/1352458515599075

25. Quintana E, Coll C, Salavedra-Pont J, et al. Cognitive impairment in early stages of multiple sclerosis is associated with high cerebrospinal fluid levels of chitinase 3-like 1 and neurofilament light chain. Eur $J$ Neurol. 2018;25(9):1189-1191. doi:10.1111/ ene. 13687

26. Summers M, Swanton J, Fernando K, et al. Cognitive impairment in multiple sclerosis can be predicted by imaging early in the disease. J Neurol Neurosurg Psychiatry. 2008;79(8):955-958. doi:10.1136/jnnp.2007.138685

27. Jønsson A, Andresen J, Storr L, Tscherning T, Sørensen PS, Ravnborg M. Cognitive impairment in newly diagnosed multiple sclerosis patients: a 4-year follow-up study. J Neurol Sci. 2006;245(1-2):77-85. doi:10.1016/j.jns.2005.09.016

28. Wallach AI, Waltz M, Casper TC, et al. Cognitive processing speed in pediatric-onset multiple sclerosis: baseline characteristics of impairment and prediction of decline. Multiple Scl J. 2019;26 (14):1352458519891984. doi:10.1177/1352458519891984

29. Faiss J, Dähne D, Baum K, et al. Reduced magnetisation transfer ratio in cognitively impaired patients at the very early stage of multiple sclerosis: a prospective, multicenter, cross-sectional study. BMJ Open. 2014;4:4. doi:10.1136/bmjopen-2013-004409

30. DiGiuseppe G, Blair M, Morrow SA. Prevalence of cognitive impairment in newly diagnosed relapsing-remitting multiple sclerosis. Int J MS Care. 2018;20(4):153-157. doi:10.7224/ 1537-2073.2017-029 
31. Ruet A, Deloire M, Hamel D, Ouallet J-C, Petry K, Brochet B. Cognitive impairment, health-related quality of life and vocational status at early stages of multiple sclerosis: a 7-year longitudinal study. J Neurol. 2013;260(3):776-784. doi:10.1007/ s00415-012-6705-1

32. Pitteri M, Romualdi C, Magliozzi R, Monaco S, Calabrese M. Cognitive impairment predicts disability progression and cortical thinning in MS: an 8-year study. Multiple Scl J. 2017;23 (6):848-854. doi:10.1177/1352458516665496

33. Berrigan LI, LeFevre J-A, Rees LM, Berard J, Freedman MS, Walker LA. Cognition in early relapsing-remitting multiple sclerosis: consequences may be relative to working memory. $J$ Int Neuropsychol Soc. 2013;19(8):938. doi:10.1017/ S1355617713000696

34. Deloire M, Salort E, Bonnet M, et al. Cognitive impairment as marker of diffuse brain abnormalities in early relapsing remitting multiple sclerosis. J Neurol Neurosurg Psychiatry. 2005;76 (4):519-526. doi:10.1136/jnnp.2004.045872

35. Deloire M, Ruet A, Hamel D, Bonnet M, Brochet B. Early cognitive impairment in multiple sclerosis predicts disability outcome several years later. Multiple Scl J. 2010;16(5):581-587. doi: $10.1177 / 1352458510362819$

36. Bodini B, Cercignani M, Khaleeli Z, et al. Corpus callosum damage predicts disability progression and cognitive dysfunction in primary-progressive MS after five years. Hum Brain Mapp. 2013;34(5):1163-1172. doi:10.1002/hbm.21499

37. Feuillet L, Reuter F, Audoin B, et al. Early cognitive impairment in patients with clinically isolated syndrome suggestive of multiple sclerosis. Multiple Scl J. 2007;13(1):124-127. doi:10.1177/ 1352458506071196

38. López-Góngora M, Escartín A, Martínez-Horta $\mathrm{S}$, et al. Neurophysiological evidence of compensatory brain mechanisms in early-stage multiple sclerosis. PLoS One. 2015;10(8): e0136786. doi:10.1371/journal.pone.0136786

39. Nourbakhsh B, Nunan-Saah J, Maghzi A-H, et al. Longitudinal associations between MRI and cognitive changes in very early MS. Mult Scler Relat Disord. 2016;5:47-52. doi:10.1016/j. msard.2015.10.010

40. Okada K, Kobata M, Sennari Y, et al. Levels of nitric oxide metabolites in cerebrospinal fluid correlate with cognitive impairment in early stage multiple sclerosis. $J$ Neurol Neurosurg Psychiatry. 2017;88(10):892-893. doi:10.1136/jnnp2017-315585

41. Deloire MS, Bonnet M, Salort E, et al. How to detect cognitive dysfunction at early stages of multiple sclerosis? Multiple Scl J. 2006;12(4):445-452. doi:10.1191/1352458506ms 1 289 oa

42. Louapre C, Perlbarg V, García-Lorenzo D, et al. Brain networks disconnection in early multiple sclerosis cognitive deficits: an anatomofunctional study. Hum Brain Mapp. 2014;35 (9):4706-4717. doi:10.1002/hbm.22505

43. Schulz D, Kopp B, Kunkel A, Faiss JH. Cognition in the early stage of multiple sclerosis. J Neurol. 2006;253(8):1002-1010. doi:10.1007/s00415-006-0145-8

44. Glanz B, Holland C, Gauthier S, et al. Cognitive dysfunction in patients with clinically isolated syndromes or newly diagnosed multiple sclerosis. Multiple Scl J. 2007;13(8):1004-1010. doi:10.1177/1352458507077943

45. Penny S, Khaleeli Z, Cipolotti L, Thompson A, Ron M. Early imaging predicts later cognitive impairment in primary progressive multiple $\begin{array}{lll}\text { sclerosis. Neurology. 2010;74(7):545-552. doi:10.1212/ } & \end{array}$ WNL.0b013e3181cff6a6

46. Morelli ME, Baldini S, Sartori A, et al. Early putamen hypertrophy and ongoing hippocampus atrophy predict cognitive performance in the first ten years of relapsing-remitting multiple sclerosis. Neurol Sci. 2020;1-12.
47. Reuter F, Zaaraoui W, Crespy L, et al. Frequency of cognitive impairment dramatically increases during the first 5 years of multiple sclerosis. J Neurol Neurosurg Psychiatry. 2011;82 (10):1157-1159. doi:10.1136/jnnp.2010.213744

48. Planche V, Ruet A, Coupé P, et al. Hippocampal microstructural damage correlates with memory impairment in clinically isolated syndrome suggestive of multiple sclerosis. Multiple Scl $\mathrm{J}$. 2017;23(9):1214-1224. doi:10.1177/1352458516675750

49. Pitteri M, Ziccardi S, Dapor C, Guandalini M, Calabrese M. Lost in classification: lower cognitive functioning in apparently cognitive normal newly diagnosed RRMS patients. Brain Sci. 2019;9 (11):321. doi:10.3390/brainsci9110321

50. Wybrecht D, Reuter F, Pariollaud F, et al. New brain lesions with no impact on physical disability can impact cognition in early multiple sclerosis: a ten-year longitudinal study. PLoS One. 2017;12(11):e0184650. doi:10.1371/journal.pone.01 84650

51. Zaaraoui W, Reuter F, Rico A, et al. Occurrence of neuronal dysfunction during the first 5 years of multiple sclerosis is associated with cognitive deterioration. J Neurol. 2011;258 (5):811-819. doi:10.1007/s00415-010-5845-4

52. Dekker I, Eijlers A, Popescu V, et al. Predicting clinical progression in multiple sclerosis after 6 and 12 years. Eur $j$ Neurol. 2019;26(6):893-902. doi:10.1111/ene.13904

53. Jongen PJ, Wesnes K, van Geel B, et al. Relationship between working hours and power of attention, memory, fatigue, depression and self-efficacy one year after diagnosis of clinically isolated syndrome and relapsing remitting multiple sclerosis. PLoS One. 2014;9(5):e96444. doi:10.1371/journal. pone.0096444

54. Forn C, Rocca MA, Valsasina P, et al. Functional magnetic resonance imaging correlates of cognitive performance in patients with a clinically isolated syndrome suggestive of multiple sclerosis at presentation: an activation and connectivity study. Multiple Scl J. 2012;18(2):153-163. doi:10.1177/ 1352458511417744

55. de Rodez Benavent SA, Nygaard GO, Harbo HF, et al. Fatigue and cognition: pupillary responses to problem-solving in early multiple sclerosis patients. Brain Behav. 2017;7(7):e00717. doi:10.1002/brb3.717

56. Jongen PJ, Wesnes K, van Geel B, et al. Does self-efficacy affect cognitive performance in persons with clinically isolated syndrome and early relapsing remitting multiple sclerosis? Mult Scler Int. 2015;2015. doi:10.1155/2015/960282

57. Labiano-Fontcuberta A, Martínez-Ginés ML, Aladro Y, et al. A comparison study of cognitive deficits in radiologically and clinically isolated syndromes. Multiple Scl J. 2016;22 (2):250-253. doi:10.1177/1352458515591072

58. Ruano L, Portaccio E, Goretti B, et al. Age and disability drive cognitive impairment in multiple sclerosis across disease subtypes. Multiple Scl J. 2017;23(9):1258-1267. doi:10.1177/ 1352458516674367

59. Caceres F, Vanotti S, Benedict R, Group RW. Cognitive and neuropsychiatric disorders among multiple sclerosis patients from Latin America: results of the RELACCEM study. Mult Scler Relat Disord. 2014;3(3):335-340. doi:10.1016/j. msard.2013.10.007

60. Glanz BI, Healy BC, Hviid LE, Chitnis T, Weiner HL. Cognitive deterioration in patients with early multiple sclerosis: a 5-year study. J Neurol Neurosurg Psychiatry. 2012;83(1):38-43. doi:10.1136/jnnp.2010.237834

61. Anhoque CF, Biccas-Neto L, Domingues S, Teixeira A, Domingues R. Cognitive impairment and optic nerve axonal loss in patients with clinically isolated syndrome. Clin Neurol Neurosurg. 2013;115(7):1032-1035. doi:10.1016/j. clineuro.2012.10.025 
62. Reuter F, Zaaraoui W, Crespy L, et al. Cognitive impairment at the onset of multiple sclerosis: relationship to lesion location. Multiple Scl J. 2011;17(6):755-758. doi:10.1177/ 1352458511398265

63. Anhoque CF, Biccas Neto L, Domingues SCA, Teixeira AL, Domingues RB. Cognitive impairment in patients with clinically isolated syndrome. Dementia Neuropsychol. 2012;6(4):266-269. doi:10.1590/S1980-57642012DN06040011

64. Potagas C, Giogkaraki E, Koutsis G, et al. Cognitive impairment in different MS subtypes and clinically isolated syndromes. $J \quad$ Neurol Sci. 2008;267(1-2):100-106. doi:10.1016/j. jns.2007.10.002

65. Achiron A, Barak Y. Cognitive impairment in probable multiple sclerosis. J Neurol Neurosurg Psychiatry. 2003;74(4):443-446. doi:10.1136/jnnp.74.4.443

66. Anhoque CF, Biccas-Neto L, Domingues SCA, Teixeira AL, Domingues RB. Cognitive impairment is correlated with reduced quality of life in patients with clinically isolated syndrome. Arq Neuropsiquiatr. 2013;71(2):74-77. doi:10.1590/S0004282X2013005000004

67. Julian L, Serafin D, Charvet L, et al. Cognitive impairment occurs in children and adolescents with multiple sclerosis: results from a United States network. J Child Neurol. 2013;28(1):102-107. doi:10.1177/0883073812464816

68. Pokryszko-Dragan A, Dziadkowiak E, Zagrajek $M$, et al. Cognitive performance, fatigue and event-related potentials in patients with clinically isolated syndrome. Clin Neurol Neurosurg. 2016;149:68-74. doi:10.1016/j.clineuro.2016.07.022

69. Glukhovsky L, Kurz D, Brandstadter R, et al. Depression and cognitive function in early multiple sclerosis: multitasking is more sensitive than traditional assessments. Multiple $\mathrm{Scl} \mathrm{J}$. 2020;1352458520958359.

70. Landrø NI, Celius EG, Sletvold H. Depressive symptoms account for deficient information processing speed but not for impaired working memory in early phase multiple sclerosis (MS). J Neurol Sci. 2004;217(2):211-216. doi:10.1016/j.jns.2003.10.012

71. Iaffaldano P, Viterbo RG, Goretti B, Portaccio E, Amato MP, Trojano M. Emotional and neutral verbal memory impairment in Multiple Sclerosis. J Neurol Sci. 2014;341(1-2):28-31. doi:10.1016/j.jns.2014.03.038

72. Bonnet MC, Deloire MS, Salort E, et al. Evidence of cognitive compensation associated with educational level in early relapsing-remitting multiple sclerosis. J Neurol Sci. 2006;251(1-2):23-28. doi:10.1016/j.jns.2006.08.002

73. Nourbakhsh B, Julian L, Waubant E. Fatigue and depression predict quality of life in patients with early multiple sclerosis: a longitudinal study. Eur $j$ Neurol. 2016;23(9):1482-1486. doi:10.1111/ene. 13102

74. Holland AA, Graves D, Greenberg BM, Harder LL. Fatigue, emotional functioning, and executive dysfunction in pediatric multiple sclerosis. Child Neuropsychol. 2014;20(1):71-85. doi:10.1080/09297049.2012.748888

75. Håkansson I, Johansson L, Dahle C, Vrethem M, Ernerudh J. Fatigue scores correlate with other self-assessment data, but not with clinical and biomarker parameters, in CIS and RRMS. Mult Scler Relat Disord. 2019;36:101424. doi:10.1016/j. msard.2019.101424

76. Reuter F, Del Cul A, Audoin B, et al. Intact subliminal processing and delayed conscious access in multiple sclerosis. Neuropsychologia. 2007;45(12):2683-2691. doi:10.1016/j. neuropsychologia.2007.04.010

77. Heitmann H, Haller B, Tiemann L, et al. Longitudinal prevalence and determinants of pain in multiple sclerosis: results from the German National Multiple Sclerosis Cohort study. Pain. 2020;161 (4):787-796. doi:10.1097/j.pain.0000000000001767
78. Bove R, Musallam A, Healy B, et al. Low testosterone is associated with disability in men with multiple sclerosis. Multiple Scl J. 2014;20(12):1584-1592. doi:10.1177/1352458514527864

79. Achiron A, Chapman J, Magalashvili D, et al. Modeling of cognitive impairment by disease duration in multiple sclerosis: a cross-sectional study. PLoS One. 2013;8(8):e71058. doi:10.1371/ journal.pone.0071058

80. Planche V, Ruet A, Charré-Morin J, Deloire M, Brochet B, Tourdias T. Pattern separation performance is decreased in patients with early multiple sclerosis. Brain Behav. 2017;7(8): e00739. doi:10.1002/brb3.739

81. Klineova S, Brandstadter R, Fabian MT, et al. Psychological resilience is linked to motor strength and gait endurance in early multiple sclerosis. Multiple Scl J. 2020;26(9):1111-1120. doi:10.1177/1352458519852725

82. Lanzillo R, Chiodi A, Carotenuto A, et al. Quality of life and cognitive functions in early onset multiple sclerosis. Eur j Paediatric Neurol. 2016;20(1):158-163. doi:10.1016/j. ejpn.2015.08.005

83. von Bismarck O, Dankowski T, Ambrosius B, et al. Treatment choices and neuropsychological symptoms of a large cohort of early MS. Neurol Neuroimmunol Neuroinflammation. 2018;5:3. doi:10.1212/NXI.0000000000000446

84. Dackovic J, Pekmezovic T, Mesaros S, et al. The Rao's Brief Repeatable Battery in the study of cognition in different multiple sclerosis phenotypes: application of normative data in a Serbian population. Neurol Sci. 2016;37(9):1475-1481. doi:10.1007/ s10072-016-2610-1

85. Skorve E, Lundervold AJ, Torkildsen Ø, Myhr K-M. The Norwegian translation of the brief international cognitive assessment for multiple sclerosis (BICAMS). Mult Scler Relat Disord. 2019;36:101408. doi:10.1016/j.msard.2019.101408

86. Landmeyer NC, Dzionsko I, Brockhoff L, et al. The agony of choice? Preserved affective decision making in early multiple sclerosis. Front Neurol. 2020;11:914. doi:10.3389/ fneur.2020.00914

87. Štecková T, Hluštík P, Sládková V, Odstrčil F, Mareš J, Kaňovský P. Thalamic atrophy and cognitive impairment in clinically isolated syndrome and multiple sclerosis. J Neurol Sci. 2014;342(1-2):62-68. doi:10.1016/j.jns.2014.04.026

88. Meijer KA, Eijlers AJ, Geurts JJ, Schoonheim MM. Staging of cortical and deep grey matter functional connectivity changes in multiple sclerosis. J Neurol Neurosurg Psychiatry. 2018;89 (2):205-210. doi:10.1136/jnnp-2017-316329

89. Wilting J, Rolfsnes HO, Zimmermann H, et al. Structural correlates for fatigue in early relapsing remitting multiple sclerosis. Eur Radiol. 2016;26(2):515-523. doi:10.1007/s00330-015-38572

90. Simioni S, Amarù F, Bonnier G, et al. MP2RAGE provides new clinically-compatible correlates of mild cognitive deficits in relapsing-remitting multiple sclerosis. $J$ Neurol. 2014;261 (8):1606-1613. doi:10.1007/s00415-014-7398-4

91. Mokhber N, Azarpazhooh A, Orouji E, et al. Cognitive dysfunction in patients with multiple sclerosis treated with different types of interferon beta: a randomized clinical trial. J Neurol Sci. 2014;342(1-2):16-20. doi:10.1016/j.jns.2014.01.038

92. Tortorella C, Romano R, Direnzo V, et al. Load-dependent dysfunction of the putamen during attentional processing in patients with clinically isolated syndrome suggestive of multiple sclerosis. Multiple Scl J. 2013;19(9):1153-1160. doi:10.1177/ 1352458512473671

93. Penner I-K, Stemper B, Calabrese P, et al. Effects of interferon beta- $1 \mathrm{~b}$ on cognitive performance in patients with a first event suggestive of multiple sclerosis. Multiple Scl j. 2012;18 (10):1466-1471. doi:10.1177/1352458512442438 
94. Audoin B, Zaaraoui W, Reuter F, et al. Atrophy mainly affects the limbic system and the deep grey matter at the first stage of multiple sclerosis. J Neurol Neurosurg Psychiatry. 2010;81 (6):690-695. doi:10.1136/jnnp.2009.188748

95. Staffen W, Mair A, Zauner H, et al. Cognitive function and fMRI in patients with multiple sclerosis: evidence for compensatory cortical activation during an attention task. Brain. 2002;125 (6):1275-1282. doi:10.1093/brain/awf125

96. Cirillo S, Rocca MA, Ghezzi A, et al. Abnormal cerebellar functional MRI connectivity in patients with paediatric multiple sclerosis. Multiple Scl J. 2016;22(3):292-301. doi:10.1177/ 1352458515592191

97. Mathiesen HK, Jonsson A, Tscherning T, et al. Correlation of global $\mathrm{N}$-acetyl aspartate with cognitive impairment in multiple sclerosis. Arch Neurol. 2006;63(4):533-536. doi:10.1001/archneur.63.4.533

98. Leavitt VM, Brandstadter R, Fabian M, et al. Dissociable cognitive patterns related to depression and anxiety in multiple sclerosis. Multiple Scl J. 2020;26(10):1247-1255. doi:10.1177/ 1352458519860319

99. Shaheen HA, Sayed SS, Daker LI, AbdelAziz HE, Taha MA. Does vitamin D deficiency predict early conversion of clinically isolated syndrome? A preliminary Egyptian study. Int J Neurosci. 2018;128(10):946-951. doi:10.1080/00207454.2018.1446954

100. Johnen A, Elpers C, Riepl E, et al. Early effective treatment may protect from cognitive decline in paediatric multiple sclerosis. Eur J Paediatric Neurol. 2019;23(6):783-791. doi:10.1016/j. ejpn.2019.08.007

101. Kocer B, Unal T, Nazliel B, et al. Evaluating sub-clinical cognitive dysfunction and event-related potentials (P300) in clinically isolated syndrome. Neurol Sci. 2008;29(6):435-444. doi:10.1007/ s10072-008-1020-4

102. Nygaard GO, Sigrid A, Harbo HF, et al. Eye and hand motor interactions with the Symbol Digit Modalities Test in early multiple sclerosis. Mult Scler Relat Disord. 2015;4(6):585-589. doi:10.1016/j.msard.2015.08.003

103. Gajamange S, Shelton A, Clough M, White O, Fielding J, Kolbe S. Functional correlates of cognitive dysfunction in clinically isolated syndromes. PLoS One. 2019;14(7):e219590. doi:10.1371/journal.pone. 0219590

104. Köhler W, Fischer M, Bublak P, et al. Information processing deficits as a driving force for memory impairment in MS: a cross-sectional study of memory functions and MRI in early and late stage MS. Mult Scler Relat Disord. 2017;18:119-127. doi:10.1016/j.msard.2017.09.026

105. Engel S, Graetz C, Salmen A, et al. Is APOE $\varepsilon 4$ associated with cognitive performance in early MS? Neurol Neuroimmunol Neuroinflammation. 2020;7:4. doi:10.1212/ NXI.0000000000000728

106. Charvet L, O'donnell E, Belman A, et al. Longitudinal evaluation of cognitive functioning in pediatric multiple sclerosis: report from the US Pediatric Multiple Sclerosis Network. Multiple Scl J. 2014;20(11):1502-1510. doi:10.1177/1352458514527862

107. Guenter W, Bieliński M, Bonek R, Borkowska A. neurochemical changes in the brain and neuropsychiatric symptoms in clinically isolated syndrome. J Clin Med. 2020;9(12):3909. doi:10.3390/ jcm9123909

108. Clough M, Millist L, Lizak N, et al. Ocular motor measures of cognitive dysfunction in multiple sclerosis I: inhibitory control. J Neurol. 2015;262(5):1130-1137. doi:10.1007/s00415-015-7645-3

109. Clough M, Mitchell L, Millist L, et al. Ocular motor measures of cognitive dysfunction in multiple sclerosis II: working memory. J Neurol. 2015;262(5):1138-1147. doi:10.1007/s00415-015-7644-4

110. Moroso A, Ruet A, Lamargue-Hamel D, et al. Preliminary evidence of the cerebellar role on cognitive performances in clinically isolated syndrome. $J$ Neurol Sci. 2018;385:1-6. doi:10.1016/j.jns.2017.11.037
111. El Ayoubi NK, Ghassan S, Said M, Allam J, Darwish H, Khoury SJ. Retinal measures correlate with cognitive and physical disability in early multiple sclerosis. J Neurol. 2016;263 (11):2287-2295. doi:10.1007/s00415-016-8271-4

112. Koubiyr I, Deloire M, Brochet B, et al. Structural constraints of functional connectivity drive cognitive impairment in the early stages of multiple sclerosis. Multiple Scl $\mathrm{J}$. 2020;1352458520971807.

113. Marstrand L, Østerberg O, Walsted T, Skov AC, Schreiber KI, Sellebjerg F. Brief international cognitive assessment for multiple sclerosis (BICAMS): a danish validation study of sensitivity in early stages of MS. Mult Scler Relat Disord. 2020;37:101458. doi:10.1016/j.msard.2019.101458

114. Kern KC, Gold SM, Lee B, et al. Thalamic-hippocampal-prefrontal disruption in relapsing-remitting multiple sclerosis. NeuroImage. 2015;8:440-447. doi:10.1016/j.nicl.2014.12.015

115. Cohen M, Brochet B, Clavelou P, et al. Cognition and quality of life in clinically isolated syndrome patients starting a disease modifying therapy in the QUALICIS study may not predict treatment response at one year. J Neurol Sci. 2017;382:73-78. doi:10.1016/j.jns.2017.09.030

116. Haase C, Tinnefeld M, Daum I, Ganz R, Haupts M, Faustmann P. Cognitive, but not mood dysfunction develops in multiple sclerosis during 7 years of follow-up. Eur Neurol. 2004;52(2):92-95. doi:10.1159/000079937

117. Hashim NA, Ismail NA, Emad EM. Evolving relationship between respiratory functions \& impairment in sleep and cognition in patients with multiple sclerosis. Mult Scler Relat Disord. 2020;46:102514. doi:10.1016/j.msard.2020.102514

118. Eva N, Adam K, Tomáš N, Martin V, Eva M, Jan L. Spatial navigation in early multiple sclerosis: a neglected cognitive marker of the disease? J Neurol. 2020;1-13.

119. Brenk A, Laun K, Haase C. Short-term cognitive training improves mental efficiency and mood in patients with multiple sclerosis. Eur Neurol. 2008;60(6):304-309. doi:10.1159/000157885

120. Patti F, Amato M, Bastianello S, et al. Effects of immunomodulatory treatment with subcutaneous interferon beta-1a on cognitive decline in mildly disabled patients with relapsing - remitting multiple sclerosis. Multiple Scl J. 2010;16(1):68-77. doi:10.1177/ 1352458509350309

121. Berard JA, Smith AM, Walker LA. A longitudinal evaluation of cognitive fatigue on a task of sustained attention in early relapsing-remitting multiple sclerosis. Int J MS Care. 2018;20 (2):55-61. doi:10.7224/1537-2073.2016-106

122. Said M, El Ayoubi NK, Hannoun S, et al. The Bayesian risk estimate at onset (BREMSO) correlates with cognitive and physical disability in patients with early multiple sclerosis. Mult Scler Relat Disord. 2018;26:96-102. doi:10.1016/j.msard.2018.09.003

123. Kraemer M, Herold M, Uekermann J, et al. Perception of affective prosody in patients at an early stage of relapsing-remitting multiple sclerosis. $J$ Neuropsychol. 2013;7(1):91-106. doi:10.1111/j.1748-6653.2012.02037.x

124. Kraemer M, Herold M, Uekermann J, et al. Theory of mind and empathy in patients at an early stage of relapsing remitting multiple sclerosis. Clin Neurol Neurosurg. 2013;115(7):1016-1022. doi:10.1016/j.clineuro.2012.10.027

125. Simioni S, Ruffieux C, Bruggimann L, Annoni J, Schluep M. Cognition, mood and fatigue in patients in the early stage of multiple sclerosis. Swiss Med Wkly. 2007;137(35-36):496-501.

126. Roca M, Torralva T, Meli F, et al. Cognitive deficits in multiple sclerosis correlate with changes in fronto-subcortical tracts. Multiple Scl J. 2008;14(3):364-369. doi:10.1177/1352458507084270

127. Olivares T, Nieto A, Sánchez M, Wollmann T, Hernández M, Barroso J. Pattern of neuropsychological impairment in the early phase of relapsing-remitting multiple sclerosis. Multiple Scl J. 2005;11(2):191-197. doi:10.1191/1352458505ms1139oa 
128. Caputi N, Matrella A, Totaro R, et al. Object decision and multiple sclerosis: a preliminary study. Funct Neurol. 2017;32(2):69. doi:10.11138/FNeur/2017.32.2.069

129. Amato M, Bartolozzi M, Zipoli V, et al. Neocortical volume decrease in relapsing-remitting MS patients with mild cognitive impairment. Neurology. 2004;63(1):89-93. doi:10.1212/01. WNL.0000129544.79539.D5

130. Zivadinov R, De Masi R, Nasuelli D, et al. MRI techniques and cognitive impairment in the early phase of relapsing-remitting multiple sclerosis. Neuroradiology. 2001;43(4):272-278. doi:10.1007/s002340000500

131. Barbu RM, Berard JA, Gresham LM, Walker LA. Longitudinal stability of cognition in early-phase relapsing-remitting multiple sclerosis: does cognitive reserve play a role? Int J MS Care. 2018;20(4):173-179. doi:10.7224/1537-2073.2016-073

132. Amato MP, Ponziani G, Pracucci G, Bracco L, Siracusa G, Amaducci L. Cognitive impairment in early-onset multiple sclerosis: pattern, predictors, and impact on everyday life in a 4-year follow-up. Arch Neurol. 1995;52(2):168-172. doi:10.1001/ archneur.1995.00540260072019

133. Amato MP, Ponziani G, Siracusa G, Sorbi S. Cognitive dysfunction in early-onset multiple sclerosis: a reappraisal after 10 years. Arch Neurol. 2001;58(10):1602-1606. doi:10.1001/ archneur.58.10.1602

134. Rojas JI, Murphy G, Sanchez F, et al. Thalamus volume change and cognitive impairment in early relapsing-remitting multiple sclerosis patients. Neuroradiol J. 2018;31(4):350-355. doi:10.1177/1971400918781977

135. Amato MP, Portaccio E, Goretti B, et al. Relevance of cognitive deterioration in early relapsing-remitting MS: a 3-year follow-up study. Multiple Scl J. 2010;16(12):1474-1482. doi:10.1177/ 1352458510380089

136. Summers M, Fisniku L, Anderson V, Miller D, Cipolotti L, Ron M. Cognitive impairment in relapsing-remitting multiple sclerosis can be predicted by imaging performed several years earlier. Multiple Scl J. 2008;14(2):197-204. doi:10.1177/ 1352458507082353

137. Panou T, Mastorodemos V, Papadaki E, Simos PG, Plaitakis A. Early signs of memory impairment among multiple sclerosis patients with clinically isolated syndrome. Behav Neurol. 2012;25(4):311-326. doi:10.1155/2012/105471

138. Rimkus C, Junqueira T, Lyra KP, et al. Corpus callosum microstructural changes correlate with cognitive dysfunction in early stages of relapsing-remitting multiple sclerosis: axial and radial diffusivities approach. Mult Scler Int. 2011;2011.

139. Prokopova B, Hlavacova N, Vlcek M, et al. Early cognitive impairment along with decreased stress-induced BDNF in male and female patients with newly diagnosed multiple sclerosis. J Neuroimmunol. 2017;302:34 40. doi:10.1016/j.jneuroim.2016.11.007

140. Wuerfel E, Weddige A, Hagmayer Y, et al. Cognitive deficits including executive functioning in relation to clinical parameters in paediatric MS patients. PLoS One. 2018;13(3):e0194873. doi:10.1371/journal.pone.0194873

141. Haase CG, Tinnefeld M, Lienemann M, Ganz RE, Faustmann PM. Depression and cognitive impairment in disability-free early multiple sclerosis. Behav Neurol. 2003;14 (1-2):39-45. doi:10.1155/2003/843760

142. Hyncicova E, Kalina A, Vyhnalek M, et al. Health-related quality of life, neuropsychiatric symptoms and structural brain changes in clinically isolated syndrome. PLoS One. 2018;13(7):e0200254. doi:10.1371/journal.pone.0200254

143. Guevara C, Villa E, Diaz V. et al. Inclusion of the Symbol Digit Modalities Test in a revised assessment of "no evidence of disease activity-4 (NEDA-4)'in Latin-American patients with multiple sclerosis. Mult Scler Relat Disord;2020. 102076. doi:10.1016/j. msard.2020.102076
144. Schmidt SL, da Silva MS, Schmidt JJ, et al. Neuropsychiatric assessments in patients with multiple sclerosis in early phases and with low disability. Neuropsychiatr Dis Treat. 2018;14:1665. doi:10.2147/NDT.S163480

145. Lima FS, Simioni S, Bruggimann L, et al. Perceived behavioral changes in early multiple sclerosis. Behav Neurol. 2007;18 (2):81-90. doi:10.1155/2007/674075

146. Simioni S, Ruffieux C, Kleeberg J, Bruggimann L, Annoni J-M, Schluep M. Preserved decision making ability in early multiple sclerosis. $J$ Neurol. 2008;255(11):1762-1769. doi:10.1007/ s00415-008-0025-5

147. Hayter AL, Salkovskis PM, Silber E, Morris RG. The impact of health anxiety in patients with relapsing remitting multiple sclerosis: misperception, misattribution and quality of life. $\mathrm{Br} J$ Clin Psychol. 2016;55(4):371-386. doi:10.1111/bjc.12106

148. Hynčicová E, Vyhnálek M, Kalina A, et al. Cognitive impairment and structural brain changes in patients with clinically isolated syndrome at high risk for multiple sclerosis. J Neurol. 2017;264 (3):482-493. doi:10.1007/s00415-016-8368-9

149. Zivadinov R, Sepcic J, Nasuelli D, et al. A longitudinal study of brain atrophy and cognitive disturbances in the early phase of relapsing-remitting multiple sclerosis. J Neurol Neurosurg Psychiatry. 2001;70(6):773-780. doi:10.1136/jnnp.70.6.773

150. Crivelli L, Farez MF, González CD, et al. Alerting network dysfunction in early multiple sclerosis. J Int Neuropsychol Soc. 2012;18(4):757. doi:10.1017/S1355617712000410

151. Cinar BP, Kösehasanoğulları G, Yigit P, Ozakbas S. Cognitive dysfunction in patients with multiple sclerosis treated with first-line disease-modifying therapy: a multi-center, controlled study using the BICAMS battery. Neurol Sci. 2017;38 (2):337-342. doi:10.1007/s10072-016-2775-7

152. Tabrizi YM, Mazhari S, Nazari MA, Zangiabadi N, Sheibani V, Azarang S. Compromised motor imagery ability in individuals with multiple sclerosis and mild physical disability: an ERP study. Clin Neurol Neurosurg. 2013;115(9):1738-1744. doi:10.1016/j. clineuro.2013.04.002

153. Uher T, Blahova-Dusankova J, Horakova D, et al. Longitudinal MRI and neuropsychological assessment of patients with clinically isolated syndrome. $J$ Neurol. 2014;261(9):1735-1744. doi:10.1007/s00415-014-7413-9

154. Margoni M, Rinaldi F, Riccardi A, Franciotta S, Perini P, Gallo P. No evidence of disease activity including cognition (NEDA-3 plus) in naïve pediatric multiple sclerosis patients treated with natalizumab. J Neurol. 2020;267(1):100-105. doi:10.1007/ s00415-019-09554-Z

155. Perumal J, Fox RJ, Balabanov R, et al. Outcomes of natalizumab treatment within 3 years of relapsing-remitting multiple sclerosis diagnosis: a prespecified 2-year interim analysis of STRIVE. BMC Neurol. 2019;19(1):116. doi:10.1186/s12883019-1337-z

156. Jakob GB, Remšak T, Jazbec SS̆, Ledinek AH, Rot U. Step initiation interferes with working memory in nondisabled patients with the earliest multiple sclerosis-a dual-task study. Gait Posture. 2017;51:201-207. doi:10.1016/j.gaitpost.2016.10.016

157. Hänninen K, Viitala M, Paavilainen $T$, et al. Thalamic atrophy without whole brain atrophy is associated with absence of 2-year NEDA in multiple sclerosis. Front Neurol. 2019;10:459. doi:10.3389/fneur.2019.00459

158. Friedova L, Motyl J, Srpova B, et al. The weak association between neurofilament levels at multiple sclerosis onset and cognitive performance after 9 years. Mult Scler Relat Disord. 2020;46:102534. doi:10.1016/j.msard.2020.102534

159. Langdon D, Amato M, Boringa J, et al. Recommendations for a brief international cognitive assessment for multiple sclerosis (BICAMS). Multiple Scl J. 2012;18(6):891-898. doi:10.1177/ 1352458511431076 
160. Smith A. Symbol Digit Modalities Test: Manual. Los Angeles, CA: Western Psychological Services; 1982.

161. Gronwall D. Paced auditory serial-addition task: a measure of recovery from concussion. Percept Mot Skills. 1977;44 (2):367-373. doi:10.2466/pms.1977.44.2.367

162. Clemens L, Langdon D. How does cognition relate to employment in multiple sclerosis? A systematic review. Mult Scler Relat Disord. 2018;26:183-191. doi:10.1016/j.msard.2018.09.018

163. Boeschoten RE, Braamse AM, Beekman AT, et al. Prevalence of depression and anxiety in multiple sclerosis: a systematic review and meta-analysis. J Neurol Sci. 2017;372:331-341. doi:10.1016/ j.jns.2016.11.067

164. Arnett PA, Strober LB. Cognitive and neurobehavioral features in multiple sclerosis. Expert Rev Neurother. 2011;11(3):411-424. doi:10.1586/ern.11.12

165. Kalb R, Beier M, Benedict RH, et al. Recommendations for cognitive screening and management in multiple sclerosis care Multiple Scl J. 2018;24(13):1665-1680. doi:10.1177/ 1352458518803785

166. Benedict RHB, Amato MP, Boringa J, et al. Brief International Cognitive Assessment for MS (BICAMS): international standards for validation. BMC Neurol. 2012;12(1):55. doi:10.1186/14712377-12-55

167. Gromisch ES, Zemon V, Benedict RHB, et al. Using a highly abbreviated California Verbal Learning Test-II to detect verbal memory deficits. Multiple Scl J. 2013;19:498-501. doi:10.1177/ 1352458512454347

168. Gromisch ES, Zemon V, Holtzer R, et al. Assessing the criterion validity of four highly abbreviated measures from the Minimal Assessment of Cognitive Function in Multiple Sclerosis (MACFIMS). Clin Neuropsychol. 2016;30(7):1032-1049. doi:10.1080/13854046.2016.1189597

169. Gromisch ES, Portnoy JG, Foley FW. Comparison of the abbreviated minimal assessment of cognitive function in multiple sclerosis (aMACFIMS) and the brief international cognitive assessment for multiple sclerosis (BICAMS). J Neurol Sci. 2018;388:70-75. doi:10.1016/j.jns.2018.03.012

170. Gromisch ES, Foley FW. Can semantic fluency be used as an alternative or additional measure in the abbreviated Minima Assessment of Cognitive Function in Multiple Sclerosis (aMACFIMS)? J Neurol Sci. 2020;410:116640. doi:10.1016/j. jns.2019.116640

171. Marrie RA, Patel R, Figley CR, et al. Diabetes and anxiety adversely affect cognition in multiple sclerosis. Mult Scler Relat Disord. 2019;27:164-170. doi:10.1016/j.msard.2018.10.018

172. Benedict RHB, Fischer JS, Archibald CJ, et al. Minimal neuropsychological assessment of MS patients: a consensus approach. Clin Neuropsychol. 2002;16:381-397. doi:10.1076/clin.16.3.381.13859
173. Rao S. A manual for the brief repeatable battery of neuropsychological tests in multiple sclerosis. Milwaukee. 1990;1696.

174. Foley FW, Benedict RHB, Gromisch ES, DeLuca J. The need for screening, assessment, and treatment for cognitive dysfunction in multiple sclerosis: results of a multidisciplinary CMSC consensus conference, September 24, 2010. Int J MS Care. 2012;14 (2):58-64. doi:10.7224/1537-2073-14.2.58

175. Gromisch ES, Kulas JF, Altalib H. et al. Neuropsychological assessments and psychotherapeutic services in Veterans with multiple sclerosis: rates of utilization and their associations with socio-demographics and clinical characteristics using Veterans Health Administration-based data. Mult Scler Relat Disord;2020. 102220. doi:10.1016/j.msard.2020.102220

176. Benedict RHB, Cookfair D, Gavett R, et al. Validity of the minimal assessment of cognitive function in multiple sclerosis (MACFIMS). J Int Neuropsychol Soc. 2006;12(4):549-558. doi:10.1017/S1355617706060723

177. Sumowski JF, Rocca MA, Leavitt VM, et al. Brain reserve and cognitive reserve in multiple sclerosis: what you've got and how you use it. Neurology. 2013;80(24):2186-2193. doi:10.1212/ WNL.0b013e318296e $98 \mathrm{~b}$

178. Schwartz CE, Ayandeh A, Ramanathan M, et al. Reserve-building activities in multiple sclerosis patients and healthy controls: a descriptive study. BMC Neurol. 2015;15:135. doi:10.1186/ s12883-015-0395-0

179. Andaloro A, Russo M, Pastura C, et al. Is there a correlation between dyslipidemia and cognitive impairment in patients with multiple sclerosis? Int J Neurosci. 2020;1-6.

180. Owji M, Ashraf-Ganjouei A, Sahraian MA, Bidadian M, Ghadiri F, Moghadasi AN. The relationship between cognitive function and body mass index in multiple sclerosis patients. Mult Scler Relat Disord. 2019;32:37-40. doi:10.1016/j. msard.2019.04.024

181. Noori H, Gheini MR, Rezaeimanesh N, et al. The correlation between dyslipidemia and cognitive impairment in multiple sclerosis patients. Mult Scler Relat Disord. 2019;36:101415. doi:10.1016/j.msard.2019.101415

182. Hernández-Ledesma AL, Rodríguez-Méndez AJ, Gallardo-Vidal LS, et al. Lipid profile: causal relationship on cognitive performance in multiple sclerosis? Mol Biol Rep. 2020;47 (12):9667-9676. doi:10.1007/s11033-020-06011-3

183. Moher D, Liberati A, Tetzlaff J, Altman DG. The PRISMA Group (2020). Preferred Reporting Items for Systematic Reviews and Meta Analyses: The PRISMA Statement PLoS Med6(7): e1000097. doi:10.1371/journal.pmed.1000097
Neuropsychiatric Disease and Treatment

\section{Publish your work in this journal}

Neuropsychiatric Disease and Treatment is an international, peerreviewed journal of clinical therapeutics and pharmacology focusing on concise rapid reporting of clinical or pre-clinical studies on a range of neuropsychiatric and neurological disorders. This journal is indexed on PubMed Central, the 'PsycINFO' database and CAS, an is the official journal of The International Neuropsychiatric Association (INA). The manuscript management system is completely online and includes a very quick and fair peer-review system, which is all easy to use. Visit http://www.dovepress.com/testimonials.php to read real quotes from published authors. 